\title{
Mesenchymal Stem Cell-Derived Exosomes: A Promising Therapeutic Ace Card to Address Autoimmune Diseases
}

\author{
Hussein Baharlooi ${ }^{1}$, Maryam Azimi ${ }^{1,2}$, Zahra Salehi ${ }^{1}$, Maryam Izad ${ }^{1,3}$ \\ ${ }^{1}$ Department of Immunology, School of Medicine, Tehran University of Medical Sciences, Tehran, Iran \\ ${ }^{2}$ Immunology Research Center, Institute of Immunology and Infectious Diseases, Iran University of Medical Sciences, Tehran, Iran \\ ${ }^{3}$ Multiple Sclerosis Research Center, Neuroscience Institute, Tehran University of Medical Sciences, Tehran, Iran
}

With the development of novel treatments for autoimmune disorders, it has become a popular research focus which mesenchymal stem cells (MSCs) have the capacity to counteract with autoimmune diseases progression. One of the underlying mechanisms behind their activities is the release of extracellular vesicles especially exosomes. MSC-derived exosomes are hypoimmunogenic nanocarriers which contain numerous immunoregulatory factors and similar to other exosomes, are able to pass through boundaries like the blood-brain barrier (BBB). Accumulating evidence provided by animal studies has demonstrated that MSC-derived exosomes, as a novel therapy, can re-induce self-tolerance, without subsequent complications reported for other treatments. Therefore, therapeutic applications of MSC-derived exosomes are contributing to core advances in the field of autoimmune diseases. Here, we briefly describe the biological characteristics of MSC-derived exosomes and review the experimentally verified outcomes for autoimmune disease therapy purposes.

Keywords: Mesenchymal stem cell, Exosome, Therapeutics, Immunomodulation, Autoimmune diseases

\section{Introduction}

Mesenchymal stem cells (MSCs) are multipotent, selfrenewable, and spindle shape cells (1) which were firstly isolated from guinea-pig bone marrow and spleen by Friedenstein et al. in 1970 (2). Now, MSCs can be isolated from cord blood, umbilical cord, bone marrow, adipose tis-

Received: September 10, 2019, Accepted: November 3, 2019,

Published online: December 31, 2019

Correspondence to Maryam Izad

Department of Immunology, School of Medicine, Tehran University of Medical Sciences, No. 226, Qods St., Keshavarz Blvd., Tehran 1416753955, Iran

Tel: +98-21-88896694, Fax: +98-21-88896696

E-mail: izadm@sina.tums.ac.ir

(c) This is an open-access article distributed under the terms of the Creative Commons Attribution Non-Commercial License (http://creativecommons.org/ licenses/by-nc/4.0/), which permits unrestricted non-commercial use, distribution, and reproduction in any medium, provided the original work is properly cited.

Copyright (c) 2020 by the Korean Society for Stem Cell Research sue, and many other tissues $(3,4)$. The single connecting feature of all these tissues is the presence of perivascular space around the blood vessels where pericytes come off and differentiate into MSCs after vessels got inflamed or injured. According to their common origin, pericytes and MSCs both are negative for CD34, CD45, CD56 and positively express CD29, CD44, CD73, CD90, CD105, CD146 (5-7). MSCs are functionally defined based on their capacity to produce molecules that provide a regenerative and immunoregulatory milieu. Moreover, these multipotent cells can differentiate into a closely related family of cells in vitro or following transplantation and subsequently recover the damages. However, recent findings have reported that MSCs do not significantly differentiate into other lineages in vivo under normal condition (8). Consequently in a new paradigm, Arnold Caplan coined "Medical Signaling Cell" for MSCs to precisely express that mesenchymal stem cells dock at the sites of injury and produce regenerative and immunoregulatory components $(9,10)$. Afterwards, a great number of clinical trials 


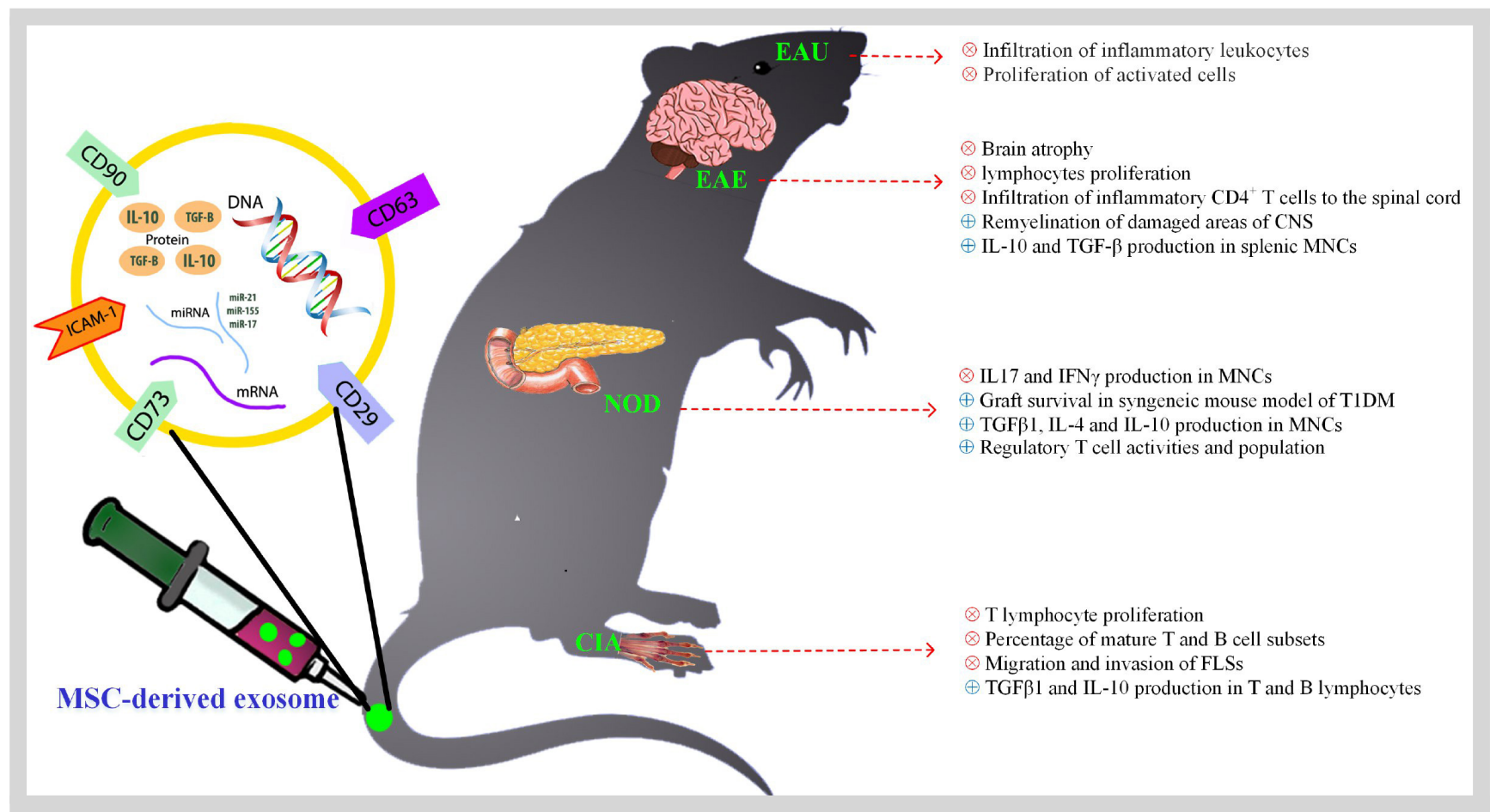

Graphical Abstract. Mesenchymal exosomes have been newly used to address impaired immune responses in some animal models of autoimmune diseases. Clinical experiments demonstrated that these vesicles successfully recover immune balance of autoreactive cells. The current picture highlights the main beneficial outcomes achieved from in vivo evaluation of MSC-derived exosomes in the mouse models.

have exploited MSC-based modalities in clinical conditions such as Type 1 diabetes mellitus, Rheumatoid Arthritis (RA), Multiple Sclerosis (MS), Crohn's disease, Lupus, kidney transplant, Graft versus Host Disease (GvHD) and many cancers (clinicaltrials.gov).

Unlike other stem cells (embryonic stem cells as well as induced pluripotent stem cells), MSCs have a dynamic immunomodulatory profile which lies on their ability to sense the injury or inflammation and then switch to the required response (11). For instance, MSCs produce transforming growth factor beta (TGF- $\beta$ ), indoleamine 2,3-dioxygenase (IDO), nitric oxide (NO), soluble HLA-G, and prostaglandin E2 (PGE2) in response to high concentration of interferon gamma (IFN $\gamma$ ), tumor necrosis factor alpha (TNF- $\alpha$ ), and toll like receptor 3 (TLR3) agonists (11-13). This reaction activates $\mathrm{CD} 4^{+} \mathrm{CD} 25^{\mathrm{hi}} \mathrm{FoxP} 3^{+}$ regulatory $\mathrm{T}$ cells (Tregs) while inhibits natural killer cell and $\mathrm{T}$ cell responses (11-13). In contrast, low level of inflammatory agents and TLR4 agonists, decrease IDO, NO, PGE2 production and increase expression of pro-inflammatory cytokines (CXCL9, CXCL10, MIP-1 $\alpha$, MIP-1 $\beta$, CCL5), indicating their double-edged sword function within the immune system (14). Accumulating investigations have demonstrated that these factors are mainly delivered through direct secretions of soluble molecules and release of extracellular vesicles particularly exosomes.

\section{Exosomes}

As shown in Table 1 (15-20), exosomes are one of the nanoscale cell-derived extracellular vesicles (EV) with 30 $100 \mathrm{~nm}$ diameter (15). Exosomes were first thought to be required for discarding unnecessary proteins out of the cells and termed as "garbage cans" (21). Later, they were introduced as gulps of cytosol delivering bioactive molecules especially proteins and small RNAs (like microRNAs) in intercellular communications. Recent investigation have shown that exosomes transfer bioactive molecules among cells and therefore is able to play an essential role in pathological conditions including Alzheimer's disease (22), transmissible spongiform encephalopathies (23), Parkinson's disease (24), and amyotrophic lateral sclerosis (25) or could be employed as nanoscale platforms for drug delivery.

Constitutive shedding of exosomes is mostly reported for immune cells (i.e. MSCs, lymphocytes, mast cells and dendritic cells) and non-immune cells particularly tumor cells $(26,27)$. Additionally, interaction between T lympho- 
Table 1. Commonalities and diversities of EVs

\begin{tabular}{|c|c|c|c|}
\hline $\begin{array}{l}\text { Features\Type of } \\
\text { vesicle }\end{array}$ & Exosome & Ectosome or Microvesicle or Microparticle & Apoptotic body \\
\hline $\begin{array}{l}\text { The most frequent } \\
\text { biomarkers }\end{array}$ & $\begin{array}{l}\text { CD9, CD63, CD81 (15), Alix (16), } \\
\text { Tsg101 }(16,17)\end{array}$ & No common marker (18) & $\begin{array}{l}\text { Annexin V, Phosphatidylserine, } \\
\text { Thrombospondin, C3b (19) }\end{array}$ \\
\hline Size (nm) & $30 \sim 100$ & $100 \sim 1000$ & $500 \sim 4000$ \\
\hline Stemed from & $\begin{array}{l}\text { Intraluminal microvesicles which } \\
\text { are originated from endosomal } \\
\text { pathway, pass through plasma } \\
\text { membrane via exocytosis }\end{array}$ & $\begin{array}{l}\text { Plasma membrane budding of activated } \\
\text { cells including human neutrophils, tumor } \\
\text { cells, erythrocytes, and polymorpho- } \\
\text { nuclear leukocytes (20) }\end{array}$ & $\begin{array}{l}\text { Plasma membrane of apoptotic } \\
\text { cells containing cell fragments }\end{array}$ \\
\hline
\end{tabular}

Table 2. The content of mesenchymal-derived exosomes

\begin{tabular}{|c|c|c|c|}
\hline Component(s) & Function(s) & Source(s) & Reference(s) \\
\hline hCAP-18/LL-37 & Antibacterial & hMSC & (35) \\
\hline SOX2, Nanog, POU5F1A/B & Critical role in multipotency of MSC & hMSC & $(36)$ \\
\hline $\begin{array}{l}\text { Transforming Growth } \\
\text { Factor } \beta 1 \text { (TGF- } \beta 1 \text { ) }\end{array}$ & Inhibits lymphocyte proliferation and differentiation & hMSC & $(37,38)$ \\
\hline Interleukin 6 (IL-6) & $\begin{array}{l}\text { IL-10 and inducer } \\
\text { Acute phase reaction enhancer }\end{array}$ & hMSC & $(38)$ \\
\hline Interleukin 10 (IL-10) & $\begin{array}{l}\mathrm{T} \text { cell proliferation suppressor } \\
\text { Regulatory } \mathrm{T} \text { cell inducer }\end{array}$ & pMSC & $(39)$ \\
\hline $\begin{array}{l}\text { Hepatocyte Growth Factor } \\
\text { (HGF) }\end{array}$ & $\begin{array}{l}\text { Decrease antigen presenting capacity of Dendritic cells and suppress } \\
\mathrm{T} \text { cell response }\end{array}$ & hMSC & $(40,41)$ \\
\hline PGE-2 & $\begin{array}{l}\text { T cell proliferation suppressor } \\
\text { NK cell proliferation suppressor }\end{array}$ & hMSC & $(42)$ \\
\hline $\operatorname{miR}-155$ & $\begin{array}{l}\text { Pro and anti-inflammatory miRNA based depending on stimulant } \\
\text { involved }\end{array}$ & $\mathrm{mMSC}$ & $(43)$ \\
\hline miR-146a & Anti-inflammatory miRNA & hMSC & $(36)$ \\
\hline miR-181c & Negatively affects NF- $\kappa$ B importin on nuclear membrane & hMSC & $(44)$ \\
\hline $\operatorname{miR}-17$ & $\begin{array}{l}\text { Anti NLRP3 inflammasome signaling pathway } \\
\text { Targets E-selectin }\end{array}$ & hMSC, mMSC & $(36,45)$ \\
\hline $\operatorname{miR}-21$ & Anti TLR4 signaling pathway & hMSC & $(36,46)$ \\
\hline miR-10a & Endothelial inflammation and senescence regulator & hMSC & (36) \\
\hline miR-92a & Targets MKK4 kinase upon TLR signaling pathway in macrophages & hMSC & $(36)$ \\
\hline miR-99b & $\begin{array}{l}\text { Downregulates expression of IL- } 1 \beta, \mathrm{IL}-6 \text {, and IL- } 12 \text { by targeting either } \\
\text { TNF- } \alpha \text { and TNF- } \alpha \text { superfamily member } 4 \text { receptor genes }\end{array}$ & hMSC & (36) \\
\hline
\end{tabular}

hMSC: human-derived MSC, mMSC: mouse-derived MSC, pMSC: porcine-derived MSC.

cytes and antigen presenting cells strongly induce the release of the exosomes bearing TCR/CD3/zeta complex (28) and MHC II-peptide (29), respectively. It was lately demonstrated that in hypoxic preconditioning and presence of lipopolysaccharide, MSCs significantly enhance the release of exosomes which shuttle anti-inflammatory agents to polarize macrophages into the M2 phenotype $(30,31)$.

Generally, extracellular vesicles affect the neighboring cells via two different strategies: 1) fusion dependent 2) fusion independent. The first mechanism takes place when vesicle is taken up by a recipient cell. There are two types of fusions: 1) direct fusion of the extracellular vesi- cle with the plasma membrane of recipient cell that requires receptor-ligand interactions 2) Back fusion which confers to the endocytosis of vesicle by the recipient cell and subsequently incorporation of vesicle with endosome's membrane $(32,33)$. In fusion independent manner, the vesicle and recipient cells interact with each other, like when exosomes bearing MHC-peptide are being specifically attached to the $\mathrm{T}$ cell receptor (TCR) on T cells (34).

\section{MSC-Derived Exosome Therapy: Cons and Pros}

As shown in Table 2 (35-46), recent findings depicted that MSC-derived exosomes deliver various cytoplasmatic 
constituents of the MSC secretomes, relevant to the stemness, angiogenesis, and particularly inflammatory factors. They were first used in 2010 for regeneration of tissues in a mouse model of myocardial ischemia/reperfusion injury (47) and are extensively on investigations at present. As a cell-free therapeutic tools provided a potential opportunity to unlock existing boundaries of cell therapy for autoimmune diseases. Exosomes introduce several advantages including capacity to cross the barriers (blood-brain barrier, capillaries) (48) and small enough to evade from being cleared by reticuloendothelial system (RES) (49). In addition to their general characteristics, MSC-derived exosomes are normally hypo-immunogenic due to the lack of MHC-II and low expression of MHC-I similar to their parental cells (50). It has also been revealed that MSCs can produce higher amount of exosomes compared with human cell lines like human embryonic kidney (HEK) and human acute monocytic leukemia (THP-1); Therefore, MSCs appear to be one of the best sources for high amount of immunoregulatory exosomes $(51,52)$.

Despite therapeutic advantages of MSC-derived exosomes, quantification of their protein profile and more importantly durability of cryopreserved exosomes as well as their in vivo tracking are still effortful. Regarding frozen exosomes, Cosenza et al. (53) analyzed functions of cryopreserved MSC-derived exosomes compared to freshly isolated exosomes and demonstrated that storage destabilize the integrity of membrane, leading to leakage of its content, aggregation of vesicles, and decrease in their immunosuppressive capacity. MSC-derived exosomes obviously express both the common MSC markers, such as CD44, CD90, and CD73 and markers of exosomes, CD9, CD63, and CD81 (51). These markers are used to track exosomes especially for drug delivery. Alternatively, cell tracing dyes can also help to chase exosomes in vivo. For instance, intravenous (i.v.) administration of Vybrant Cell Tracer DiD- or DiI-labeled exosomes to the mouse model of acute kidney injury, were used to monitor accumulation of MSC-derived exosomes. In this investigation, exosomes were mostly found in kidney, spleen, liver, and lung as filtering organs of the body (54). Apart from utilization of fluorescent molecules to chase organ localization of EVs, lower sensitivity of fluorophores negatively affect pharmacokinetic analysis of their applications (especially for quantification of exosome accumulated in a target tissue) (55). Radiolabeling with iodine-125 and bioluminescence emitted from luciferase provide a more practical solution for whole-body imaging of exosome-treated animals with significantly higher sensitivity of detection (56, 57). Also, stability of B16-BL6 melanoma cell-derived exo- somes in blood circulation were evaluated using exosomes expressing a fusion protein of Gaussia luciferase-Lactadherin, a reporter protein attached to one of the exosome's trophic protein, respectively. The results indicated exosomal half-life of about 2 minutes following i.v. injection. This finding suggests short half-life of exosomes is because of their fast uptake by liver and spleen resident macrophages (56).

\section{MSC-Derived Exosome Therapy for Autoimmune Diseases}

Utilization of the MSC-derived exosomes for autoimmune diseases therapy is at early stages. Most of studies are focused on immunomodulatory effects of these small vesicles in animal models. Here we will discuss the roles of these exosomes in the treatment of autoimmune diseases.

\section{Multiple Sclerosis}

Multiple Sclerosis (MS) is a chronic autoimmune disease characterized by neuroinflammation and demyelination in the central nervous system (CNS) (58). Numerous studies have revealed activation and recruitment of autoaggressive $\mathrm{CD}^{+}{ }^{+}$and $\mathrm{CD} 8^{+} \mathrm{T}$ cells into the $\mathrm{CNS}$ as the main pathogenic players of MS $(59,60)$. Disease-modifying treatments (DMTs) especially IFN- $\beta$ are commonly prescribed to treat the affected individuals $(61,62)$. Despite their beneficial impacts, DMTs increase the risk of adverse effects including lymphopenia, lymphadenopathy, dyspnea and lipoatrophy (63-65). Hence, identification and evaluation of alternative approaches with lower side effects are necessary.

We have already demonstrated that MSCs and their activity have been altered after DMT consumption in relapsing-remitting MS patients (66). Indeed, patients own stem cells may have more deficiencies which not efficiently prevent for MS initiation and progression (67). However, MSCs can differentiate into neural cells and release neurotrophic molecules, indicating their strong neuroprotective effects for treating MS (68). Accumulating evidence has shown that MSCs can regulate autoreactive cells in a paracrine manner through secretion of inhibitory cytokines or molecules as well (69-71). MSC-derived exosomes can also induce peripheral tolerance toward autoreactive $\mathrm{T}$ cells via transferring the tolerogenic molecules to the autoreactive immune cells.

Since exosomes are lipid-bound nano-vesicles, they can cross the blood-brain barrier. Therefore, incubation of 
exosomes in presence of neurotrophic and remyelination factors elevate their therapeutic profits. Additionally, expression of receptor(s) with ability to recognize neural markers in the MSCs increase efficiency of the delivery system. In this case, Zhuang et al. (72) have administered exosomes bearing anti-inflammatory compounds such as curcumin to the EAE mouse and demonstrated that clinical symptoms of the diseases were improved.

In 2012, Mokarizadeh et al. (73) showed that MSC-derived extracellular vesicles exert immunomodulatory effects on splenic mononuclear cells (MNCs) of EAE mouse. These small vesicles not only reduced autoreactive lymphocytes proliferation, but also potentially induced MNCs to secrete significant amount of IL-10. They also demonstrated that MSC-derived vesicles contain PD-L1, galectin-1, and TGF- $\beta$, which help them with their immunoregulatory functions. This investigation proposed that MSC-derived vesicles including exosomes are capable of transferring anti-inflammatory molecules into autoreactive cells and re-inducing a self-tolerance. Later in 2018, Laso-García et al. (74) revealed that i.v. administration of MSC-derived exosomes to a progressive model of MS, Theiler's murine encephalomyelitis virus (TMEV)induced demyelinating disease, recovered the disabilities observed before treatment. They indicated that administrated MVs prompt remyelination, reduce the brain atrophy, and infiltration of inflammatory $\mathrm{CD}^{+}{ }^{+} \mathrm{T}$ cells to the spinal cord of TMEV-infected mice.

Recently, Li et al. (75) demonstrated that MSC-derived exosomes polarize microglia cells mainly into the M2 phenotype and consequently alleviate clinical scores of EAE. In this study, the balance of $M 1 / M 2$ in EAE rates significantly deviated toward M2 phenotype and their cytokines profile (IL-10 and TGF- $\beta$ ), while frequency and activity of M1 cells were decreased. Interestingly for the first time, Hosseini Shamili et al. (76) bioconjugated the MSC-derived exosomes to an aptamer which targets oligodendrocyte markers. The armed exosome improved proliferation of oligodendroglia cell line (OLN93) in vitro and reduced both inflammatory responses and demyelinated lesions in the CNS of EAE mice. These methodologies may provide a new perspective toward indirect applications of MSCs in the treatment of MS.

\section{Rheumatoid Arthritis}

Rheumatoid arthritis (RA) is an inflammatory disease with unknown etiology that causes articular destruction and subsequently functional loss in joints. RA immunopathogenesis is characterized by disordered innate and adaptive immunity that result in immune complex-mediated complement activation, autoreactive lymphocyte response against self-antigens, and also dysregulated cytokine networks $(77,78)$.

As with MS, there are various biological disease-modifying anti-rheumatic drugs (bDMARDs) available to control the symptoms of RA. For example, blockade of proinflammatory cytokines including GM-CSF, TNF- $\alpha$, and IL-6 with antibodies or soluble decoy receptors have been mainly utilized for patients suffering from RA for many years (79). Along with beneficial effects of immunosuppressive and immunomodulatory drugs, they present various side effects including nausea, liver problems, lymphopenia, high risk of infection, and etc. (79). There is indeed a crucial need for new treatment modules with fewer side effects. MSC-derived exosomes have been considered to exert immunosuppressive activities, supporting their application in rheumatic diseases. Although the use of exosomes derived from various origins have been studied extensively to date $(80,81)$, to date, the role of MSC-derived exosomes is still in the beginning.

In 2018, Cosenza et al. (53) showed that MSC-derived exosomes reveal anti-inflammatory impacts on $\mathrm{T}$ and $\mathrm{B}$ lymphocytes in collagen-induced arthritis (CIA) mice model. In this study, MSCs-derived exosomes effectively inhibit $\mathrm{T}$ lymphocyte proliferation in a dose-dependent manner and decreased the percentage of mature $\mathrm{T}$ and $\mathrm{B}$ cell subsets. Interestingly, exosomes increased regulatory T cell populations much better than MSCs and MSC-derived microvesicles. Further investigations confirmed that microvesicles derived from MSCs are less effective to induce TGF- $\beta$ and IL-10 production in T and B lymphocytes compared to MSCs alone (82). In 2018, Chen et al. (83) demonstrated that modified MSC-derived exosomes which contain miRNA-150, target the matrix metalloproteinase 14 (MMP14) and thereafter, decrease migration and invasion of fibroblast-like synoviocytes (FLS). They also indicated that injection of these engineered exosomes to the CIA mouse can effectively reduce the hind paw thickness and the clinical arthritic scores of animals. Another study evaluated beneficial impacts of human umbilical cord mesenchymal stem cells-derived exosomes (hUCMSC-derived exosomes) on bone destruction in CIA rats. Interestingly, the treatment reduced recruitment of inflammatory cell to the joints and prevent from joint synovial hyperplasia. The authors proposed that the underlying mechanism could be due to regulating of the imbalance of RANKL/OPG. To be clear, they showed that RANKL was decreased in serum and synovial tissues of the CIA rats, while the treatment raised the OPG concen- 
tration (84). In consensus with this study, another group demonstrated that intra-articular injection of hUCMSCderived exosomes significantly decreased autoreactive infiltering chemokines CCL2 and CXCL12 in serum and synovial fluid (85).

\section{Type 1 Diabetes Mellitus (Insulin-Dependent Diabetes Mellitus)}

Type 1 diabetes mellitus (T1DM) is an incurable and chronic autoimmune disease which is classically identified by reduced level of insulin due to autoimmune destruction of insulin-producing pancreatic $\beta$ cell, leading to hyperglycemia (86). Although underlying mechanism of disease is unknown, disruption of immune tolerance in autoreactive $\mathrm{B}$ cells, $\mathrm{CD}^{+} \mathrm{T}$ cells and particularly $\mathrm{CD} 8^{+}$cytotoxic $\mathrm{T}$ lymphocytes (CTL) are believed to contribute to the pathogenesis of type 1 diabetes. As a result, diabetic patients need exogenous insulin regiment to control their blood glucose level and avoid from consequences caused by hyperglycemia like fatigue, cataract, and also diabetic coma. Repetitive injection of insulin point to the fact that insulin titer is not stable in affected subjects and patients require a durable cure for diabetes.

In order to develop novel therapies for T1DM, researchers have taken different approaches so far. Since first whole pancreas transplantation in 1966, long-term normoglycemia has been achieved with a graft survival rate of 50 to $70 \%$ after 5 years $(87,88)$. But sequential complications including pancreatitis, thrombosis, and pseudocyst appeared in graft are major disadvantages of this surgery (89). Eventually, transplantation of endocrine part of pancreas (known as islet transplantation) is a well-developed procedure to minimize complications of insulin therapy and pancreas transplantation (90). last two methods prevent from the disease progression for a limited period of time, but can not correctify autoimmune response against the $\beta$ cells. The cure must be in the region where autoimmune response is originated.

Various strategies have been applied to recover immune tolerance at critical points of regulatory pathways. Of the different approaches, anti-CD3 antibodies nonspecifically induce $\mathrm{T}$ cell anergy by co-stimulation blockade. Thereafter, beta cells are preserved in disease established nonobese diabetic (NOD) mice (91). Traditional $\alpha$ CD3 antibodies like OKT3 were provided from mouse and could not be administered continuously for chronic diseases. This drawback is overwhelmed by humanizing the antibody sequence (92). Moreover, mitogenic effect of CD3 specific antibodies on $\mathrm{T}$ cells, owning to their cross-link- ing ability to bind to the Fc receptors on natural killer cells and monocytes, brings about a notable cytokine release (93). This problem can be solved via engineering of C-terminal sequence of antibody to stop its binding possibility to $\mathrm{Fc} \gamma$ receptors.

MSC therapy has also shown antidiabetic effects to restore immune response balance in pancreas. Ezquer et al. (94) injected GFP expressing MSCs to diabetic mouse and reported normalized $\mathrm{Th} 1 / \mathrm{Th} 2$ response in diabetic group compared to control. They also traced labeled MSCs after 7 and 65 days to be sure if MSCs differentiate into beta cells and lead to normoglycemia. Surprisingly, they found MSCs in heart and secondary lymphoid organs (like Payer's patch, inguinal lymph node, and pancreatic lymph nodes) not in pancreas. It suggests that the antidiabetic effect of MSC is due to its endocrine activity not differentiation capacity. In 2016, Nakano et al. (95) have used MSC-derived exosomes to diminish cognitive impairments of diabetic rats by repairing damaged astrocytes and more importantly neurons. Furthermore, administration of MSC-derived exosomes simultaneously with islet transplantation, suppressed proliferation of PBMCs, improved regulatory $\mathrm{T}$ cell activities and increased graft survival in syngeneic mouse model of T1DM (96). Similar to previous studies, a group of scientists also evaluated immunomodulatory effects of MSC-derived exosomes compared with control and reported significant increase of regulatory $\mathrm{T}$ cell population among splenic MNCs, accompanied by upregulation of IL-4, IL-10, TGF- $\beta$ plus downregulation of IL-17 and IFN $\gamma$ cytokines after treatment. Accordingly treatment stabilized the blood glucose and vanished the signs of diabetes (97).

\section{Uveitis}

Uveitis is an autoimmune disorder which causes severe visual disability (98). Current clinical treatment includes corticosteroids, other immunosuppressive drugs, and newly developed biologics. The long-term utilization of each is followed by serious systemic side effects and the local risk of cataracts and glaucoma $(99,100)$. Hence, most investigation intended to find localized and specific therapies. Although, it has been recently revealed that i.v. injection of MSCs improved experimental autoimmune uveitis (EAU) in animal model of uveitis (101-103), the underlying mechanisms of MSCs is not clear yet. In 2017, Bai et al. (104) showed that, human umbilical cord MSC-derived exosomes can reduce the severity of EAU. They demonstrated that MSC-derived exosomes inhibited the infiltration of inflammatory leukocytes to the eyes and 
these outcomes could, at least partly, be due to expression of CD73 on the MSCs. As expected, exosomes bearing CD73 interact with CD39 on activated immune cells and induce production of adenosine which result in proliferation inhibition. This study is the only study on the role of exosomes uveitis, indicating the importance of further investigation in this field.

\section{Conclusions}

Until last decade, the contribution of MSC-derived exosomes in the control of inflammatory responses has been less clear. As a functional vesicle derived from MSCs, exosomes have shown same beneficial impacts of the cell of origin, to suppress several autoreactive cells in autoimmune diseases. Moreover, although mesenchymal-derived exosomes expose immunomodulatory functions by self, it seems that engineering these vesicles through adding anti-inflammatory molecules and certain receptors, they can specifically target tissue/organ of interest. This attitude might consider as a potentially novel candidate to treat other autoimmune disorders like spondylitis ankylosing and scleroderma as well.

With respect to remaining challenges, more investigations are required to elucidate unclear aspects of cell-free therapy using MSC-derived exosomes in ongoing studies.

\section{Potential Conflict of Interest}

The authors have no conflicting financial interest.

\section{References}

1. Crisan M, Corselli M, Chen CW, Péault B. Multilineage stem cells in the adult: a perivascular legacy? Organogenesis 2011;7:101-104

2. Friedenstein AJ, Chailakhjan RK, Lalykina KS. The development of fibroblast colonies in monolayer cultures of guinea-pig bone marrow and spleen cells. Cell Tissue Kinet 1970;3:393-403

3. Murray IR, West CC, Hardy WR, James AW, Park TS, Nguyen A, Tawonsawatruk T, Lazzari L, Soo C, Péault B. Natural history of mesenchymal stem cells, from vessel walls to culture vessels. Cell Mol Life Sci 2014;71:13531374

4. Hassan G, Kasem I, Soukkarieh C, Aljamali M. A Simple method to isolate and expand human umbilical cord derived mesenchymal stem cells: using explant method and umbilical cord blood serum. Int J Stem Cells 2017;10:184192

5. Caplan AI. All MSCs are pericytes? Cell Stem Cell
2008;3:229-230

6. Pham H, Tonai R, Wu M, Birtolo C, Chen M. CD73, CD90, CD105 and Cadherin-11 RT-PCR screening for mesenchymal stem cells from cryopreserved human cord tissue. Int J Stem Cells 2018;11:26-38

7. Geevarghese A, Herman IM. Pericyte-endothelial crosstalk: implications and opportunities for advanced cellular therapies. Transl Res 2014;163:296-306

8. Guimarães-Camboa N, Cattaneo P, Sun Y, Moore-Morris T, Gu Y, Dalton ND, Rockenstein E, Masliah E, Peterson KL, Stallcup WB, Chen J, Evans SM. Pericytes of multiple organs do not behave as mesenchymal stem cells in vivo. Cell Stem Cell 2017;20:345-359.e5

9. Caplan AI. What's in a name? Tissue Eng Part A 2010;16: 2415-2417

10. Caplan AI. Mesenchymal stem cells: time to change the name! Stem Cells Transl Med 2017;6:1445-1451

11. Bernardo ME, Fibbe WE. Mesenchymal stromal cells: sensors and switchers of inflammation. Cell Stem Cell 2013; 13:392-402

12. Di Nicola $M$, Carlo-Stella C, Magni M, Milanesi $M$, Longoni PD, Matteucci P, Grisanti S, Gianni AM. Human bone marrow stromal cells suppress T-lymphocyte proliferation induced by cellular or nonspecific mitogenic stimuli. Blood 2002;99:3838-3843

13. Bruno S, Deregibus MC, Camussi G. The secretome of mesenchymal stromal cells: role of extracellular vesicles in immunomodulation. Immunol Lett 2015;168:154-158

14. Kyurkchiev D, Bochev I, Ivanova-Todorova E, Mourdjeva M, Oreshkova T, Belemezova K, Kyurkchiev S. Secretion of immunoregulatory cytokines by mesenchymal stem cells. World J Stem Cells 2014;6:552-570

15. Edgar JR, Eden ER, Futter CE. Hrs- and CD63-dependent competing mechanisms make different sized endosomal intraluminal vesicles. Traffic 2014;15:197-211

16. Bobrie A, Colombo M, Krumeich S, Raposo G, Théry C. Diverse subpopulations of vesicles secreted by different intracellular mechanisms are present in exosome preparations obtained by differential ultracentrifugation. J Extracell Vesicles 2012;1:18397

17. Théry C, Boussac M, Véron P, Ricciardi-Castagnoli P, Raposo G, Garin J, Amigorena S. Proteomic analysis of dendritic cell-derived exosomes: a secreted subcellular compartment distinct from apoptotic vesicles. J Immunol 2001;166:7309-7318

18. Cocucci E, Meldolesi J. Ectosomes and exosomes: shedding the confusion between extracellular vesicles. Trends Cell Biol 2015;25:364-372

19. Akers JC, Gonda D, Kim R, Carter BS, Chen CC. Biogenesis of extracellular vesicles (EV): exosomes, microvesicles, retrovirus-like vesicles, and apoptotic bodies. J Neurooncol 2013;113:1-11

20. Hess C, Sadallah S, Hefti A, Landmann R, Schifferli JA. Ectosomes released by human neutrophils are specialized functional units. J Immunol 1999;163:4564-4573

21. Johnstone RM. The Jeanne Manery-Fisher memorial lec- 
ture 1991. Maturation of reticulocytes: formation of exosomes as a mechanism for shedding membrane proteins. Biochem Cell Biol 1992;70:179-190

22. Rajendran L, Honsho M, Zahn TR, Keller P, Geiger KD, Verkade P, Simons K. Alzheimer's disease beta-amyloid peptides are released in association with exosomes. Proc Natl Acad Sci U S A 2006;103:11172-11177

23. Fevrier B, Vilette D, Archer F, Loew D, Faigle W, Vidal M, Laude H, Raposo G. Cells release prions in association with exosomes. Proc Natl Acad Sci U S A 2004;101:96839688

24. Emmanouilidou E, Melachroinou K, Roumeliotis T, Garbis SD, Ntzouni M, Margaritis LH, Stefanis L, Vekrellis K. Cell-produced alpha-synuclein is secreted in a calcium-dependent manner by exosomes and impacts neuronal survival. J Neurosci 2010;30:6838-6851

25. Gomes C, Keller S, Altevogt P, Costa J. Evidence for secretion of $\mathrm{Cu}, \mathrm{Zn}$ superoxide dismutase via exosomes from a cell model of amyotrophic lateral sclerosis. Neurosci Lett 2007;428:43-46

26. Tamai K, Tanaka N, Nakano T, Kakazu E, Kondo Y, Inoue J, Shiina M, Fukushima K, Hoshino T, Sano K, Ueno Y, Shimosegawa T, Sugamura K. Exosome secretion of dendritic cells is regulated by Hrs, an ESCRT-0 protein. Biochem Biophys Res Commun 2010;399:384-390

27. Haney MJ, Klyachko NL, Zhao Y, Gupta R, Plotnikova EG, He Z, Patel T, Piroyan A, Sokolsky M, Kabanov AV, Batrakova EV. Exosomes as drug delivery vehicles for Parkinson's disease therapy. J Control Release 2015;207:1830

28. Blanchard N, Lankar D, Faure F, Regnault A, Dumont C, Raposo G, Hivroz C. TCR activation of human T cells induces the production of exosomes bearing the TCR/CD3/ zeta complex. J Immunol 2002;168:3235-3241

29. Buschow SI, Nolte-'t Hoen EN, van Niel G, Pols MS, ten Broeke T, Lauwen M, Ossendorp F, Melief CJ, Raposo G, Wubbolts R, Wauben MH, Stoorvogel W. MHC II in dendritic cells is targeted to lysosomes or T cell-induced exosomes via distinct multivesicular body pathways. Traffic 2009;10:1528-1542

30. Lo Sicco C, Reverberi D, Balbi C, Ulivi V, Principi E, Pascucci L, Becherini P, Bosco MC, Varesio L, Franzin C, Pozzobon M, Cancedda R, Tasso R. Mesenchymal stem cell-derived extracellular vesicles as mediators of anti-inflammatory effects: endorsement of macrophage polarization. Stem Cells Transl Med 2017;6:1018-1028

31. Ti D, Hao H, Tong C, Liu J, Dong L, Zheng J, Zhao Y, Liu H, Fu X, Han W. LPS-preconditioned mesenchymal stromal cells modify macrophage polarization for resolution of chronic inflammation via exosome-shuttled let-7b. J Transl Med 2015;13:308

32. Bissig C, Gruenberg J. ALIX and the multivesicular endosome: ALIX in wonderland. Trends Cell Biol 2014;24:1925

33. Abrami L, Lindsay M, Parton RG, Leppla SH, van der Goot FG. Membrane insertion of anthrax protective anti- gen and cytoplasmic delivery of lethal factor occur at different stages of the endocytic pathway. J Cell Biol 2004; 166:645-651

34. Denzer K, van Eijk M, Kleijmeer MJ, Jakobson E, de Groot C, Geuze HJ. Follicular dendritic cells carry MHC class II-expressing microvesicles at their surface. J Immunol 2000;165:1259-1265

35. Krasnodembskaya A, Song Y, Fang X, Gupta N, Serikov V, Lee JW, Matthay MA. Antibacterial effect of human mesenchymal stem cells is mediated in part from secretion of the antimicrobial peptide LL-37. Stem Cells 2010;28: 2229-2238

36. Baglio SR, Rooijers K, Koppers-Lalic D, Verweij FJ, Pérez Lanzón M, Zini N, Naaijkens B, Perut F, Niessen HW, Baldini N, Pegtel DM. Human bone marrow- and adipose-mesenchymal stem cells secrete exosomes enriched in distinctive miRNA and tRNA species. Stem Cell Res Ther 2015;6:127

37. Spaggiari GM, Capobianco A, Becchetti S, Mingari MC, Moretta L. Mesenchymal stem cell-natural killer cell interactions: evidence that activated NK cells are capable of killing MSCs, whereas MSCs can inhibit IL-2-induced NK-cell proliferation. Blood 2006;107:1484-1490

38. Di Trapani M, Bassi G, Midolo M, Gatti A, Kamga PT, Cassaro A, Carusone R, Adamo A, Krampera $M$. Differential and transferable modulatory effects of mesenchymal stromal cell-derived extracellular vesicles on T, B and NK cell functions. Sci Rep 2016;6:24120

39. Eirin A, Zhu XY, Puranik AS, Tang H, McGurren KA, van Wijnen AJ, Lerman A, Lerman LO. Mesenchymal stem cell-derived extracellular vesicles attenuate kidney inflammation. Kidney Int 2017;92:114-124

40. Tan CY, Lai RC, Wong W, Dan YY, Lim SK, Ho HK. Mesenchymal stem cell-derived exosomes promote hepatic regeneration in drug-induced liver injury models. Stem Cell Res Ther 2014;5:76

41. Okunishi K, Dohi M, Nakagome K, Tanaka R, Mizuno S, Matsumoto K, Miyazaki J, Nakamura T, Yamamoto K. A novel role of hepatocyte growth factor as an immune regulator through suppressing dendritic cell function. J Immunol 2005; 175:4745-4753

42. Garo LP, Murugaiyan G. Contribution of MicroRNAs to autoimmune diseases. Cell Mol Life Sci 2016;73:2041-2051

43. Harding C, Heuser J, Stahl P. Receptor-mediated endocytosis of transferrin and recycling of the transferrin receptor in rat reticulocytes. J Cell Biol 1983;97:329-339

44. Bigagli E, De Filippo C, Castagnini C, Toti S, Acquadro F, Giudici F, Fazi M, Dolara P, Messerini L, Tonelli F, Luceri C. DNA copy number alterations, gene expression changes and disease-free survival in patients with colorectal cancer: a 10 year follow-up. Cell Oncol 2016;39:545558

45. Liu Y, Lou G, Li A, Zhang T, Qi J, Ye D, Zheng M, Chen Z. AMSC-derived exosomes alleviate lipopolysaccharide/ d-galactosamine-induced acute liver failure by miR-17-mediated reduction of TXNIP/NLRP3 inflammasome activa- 
tion in macrophages. EBioMedicine 2018;36:140-150

46. Ti D, Hao H, Fu X, Han W. Mesenchymal stem cells-derived exosomal microRNAs contribute to wound inflammation. Sci China Life Sci 2016;59:1305-1312

47. Lai RC, Arslan F, Lee MM, Sze NS, Choo A, Chen TS, Salto-Tellez M, Timmers L, Lee CN, El Oakley RM, Pasterkamp G, de Kleijn DP, Lim SK. Exosome secreted by MSC reduces myocardial ischemia/reperfusion injury. Stem Cell Res 2010;4:214-222

48. Choi H, Lee DS. Illuminating the physiology of extracellular vesicles. Stem Cell Res Ther 2016;7:55

49. Li SD, Huang L. Nanoparticles evading the reticuloendothelial system: role of the supported bilayer. Biochim Biophys Acta 2009;1788:2259-2266

50. Klyushnenkova E, Mosca JD, Zernetkina V, Majumdar MK, Beggs KJ, Simonetti DW, Deans RJ, McIntosh KR. $\mathrm{T}$ cell responses to allogeneic human mesenchymal stem cells: immunogenicity, tolerance, and suppression. J Biomed Sci 2005;12:47-57

51. Yeo RW, Lai RC, Zhang B, Tan SS, Yin Y, Teh BJ, Lim SK. Mesenchymal stem cell: an efficient mass producer of exosomes for drug delivery. Adv Drug Deliv Rev 2013;65: 336-341

52. Ma ZJ, Wang YH, Li ZG, Wang Y, Li BY, Kang HY, Wu $\mathrm{XY}$. Immunosuppressive effect of exosomes from mesenchymal stromal cells in defined medium on experimental colitis. Int J Stem Cells 2019. doi: 10.15283/ijsc18139. [Epub ahead of print]

53. Cosenza S, Toupet K, Maumus M, Luz-Crawford P, Blanc-Brude O, Jorgensen C, Noël D. Mesenchymal stem cells-derived exosomes are more immunosuppressive than microparticles in inflammatory arthritis. Theranostics 2018;8:1399-1410

54. Grange C, Tapparo M, Bruno S, Chatterjee D, Quesenberry PJ, Tetta C, Camussi G. Biodistribution of mesenchymal stem cell-derived extracellular vesicles in a model of acute kidney injury monitored by optical imaging. Int J Mol Med 2014;33:1055-1063

55. Meng F, Wang J, Ping Q, Yeo Y. Quantitative assessment of nanoparticle biodistribution by fluorescence imaging, revisited. ACS Nano 2018;12:6458-6468

56. Morishita M, Takahashi Y, Nishikawa M, Sano K, Kato K, Yamashita T, Imai T, Saji H, Takakura Y. Quantitative analysis of tissue distribution of the B16BL6-derived exosomes using a streptavidin-lactadherin fusion protein and iodine-125-labeled biotin derivative after intravenous injection in mice. J Pharm Sci 2015;104:705-713

57. Badr CE, Tannous BA. Bioluminescence imaging: progress and applications. Trends Biotechnol 2011;29:624-633

58. Geurts JJ, Barkhof F. Grey matter pathology in multiple sclerosis. Lancet Neurol 2008;7:841-851

59. Popescu BF, Lucchinetti CF. Pathology of demyelinating diseases. Annu Rev Pathol 2012;7:185-217

60. Salehi Z, Doosti R, Beheshti M, Janzamin E, Sahraian MA, Izad M. Differential frequency of CD8 $+\mathrm{T}$ cell subsets in multiple sclerosis patients with various clinical patterns.
PLoS One 2016;11:e159565

61. Tanasescu R, Ionete C, Chou IJ, Constantinescu CS. Advances in the treatment of relapsing-remitting multiple sclerosis. Biomed J 2014;37:41-49

62. Gholamzad M, Ebtekar M, Ardestani MS, Azimi M, Mahmodi Z, Mousavi MJ, Aslani S. A comprehensive review on the treatment approaches of multiple sclerosis: currently and in the future. Inflamm Res 2019;68:25-38

63. Nakhaei-Nejad M, Barilla D, Lee CH, Blevins G, Giuliani F. Characterization of lymphopenia in patients with MS treated with dimethyl fumarate and fingolimod. Neurol Neuroimmunol Neuroinflamm 2017;5:e432

64. Comi G, Martinelli V, Rodegher M, Moiola L, Bajenaru O, Carra A, Elovaara I, Fazekas F, Hartung HP, Hillert J, King J, Komoly S, Lubetzki C, Montalban X, Myhr KM, Ravnborg M, Rieckmann P, Wynn D, Young C, Filippi M; PreCISe Study Group. Effect of glatiramer acetate on conversion to clinically definite multiple sclerosis in patients with clinically isolated syndrome (PreCISe study): a randomised, double-blind, placebo-controlled trial. Lancet 2009; 374:1503-1511

65. Wang M, Yuan Q, Xie L. Mesenchymal stem cell-based immunomodulation: properties and clinical application. Stem Cells Int 2018;2018:3057624

66. Emamnejad R, Sahraian M, Shakiba Y, Salehi Z, Masoomi A, Imani D, Najafi F, Laribi B, Shirzad H, Izad M. Circulating mesenchymal stem cells, stromal derived factor (SDF)-1 and IP-10 levels increased in clinically active multiple sclerosis patients but not in clinically stable patients treated with beta interferon. Mult Scler Relat Disord 2019;35:233-238

67. Sargent A, Shano G, Karl M, Garrison E, Miller C, Miller RH. Transcriptional profiling of mesenchymal stem cells identifies distinct neuroimmune pathways altered by CNS disease. Int J Stem Cells 2018;11:48-60

68. Johnson TV, Bull ND, Hunt DP, Marina N, Tomarev SI, Martin KR. Neuroprotective effects of intravitreal mesenchymal stem cell transplantation in experimental glaucoma. Invest Ophthalmol Vis Sci 2010;51:2051-2059

69. Herrero C, Pérez-Simón JA. Immunomodulatory effect of mesenchymal stem cells. Braz J Med Biol Res 2010;43:425430

70. Nasri F, Mohtasebi MS, Hashemi E, Zarrabi M, Gholijani N, Sarvestani EK. Therapeutic efficacy of mesenchymal stem cells and mesenchymal stem cells-derived neural progenitors in experimental autoimmune encephalomyelitis. Int J Stem Cells 2018;11:68-77

71. Marti LC, Ribeiro AA, Hamerschlak N. Immunomodulatory effect of mesenchymal stem cells. Einstein (Sao Paulo) 2011;9:224-228

72. Zhuang X, Xiang X, Grizzle W, Sun D, Zhang S, Axtell RC, Ju S, Mu J, Zhang L, Steinman L, Miller D, Zhang HG. Treatment of brain inflammatory diseases by delivering exosome encapsulated anti-inflammatory drugs from the nasal region to the brain. Mol Ther 2011;19:1769-1779

73. Mokarizadeh A, Delirezh N, Morshedi A, Mosayebi G, 
Farshid AA, Mardani K. Microvesicles derived from mesenchymal stem cells: potent organelles for induction of tolerogenic signaling. Immunol Lett 2012;147(1-2):47-54

74. Laso-García F, Ramos-Cejudo J, Carrillo-Salinas FJ, Otero-Ortega L, Feliú A, Gómez-de Frutos M, Mecha M, Díez-Tejedor E， Guaza C, Gutiérrez-Fernández $M$. Therapeutic potential of extracellular vesicles derived from human mesenchymal stem cells in a model of progressive multiple sclerosis. PLoS One 2018;13:e0202590

75. Li Z, Liu F, He X, Yang X, Shan F, Feng J. Exosomes derived from mesenchymal stem cells attenuate inflammation and demyelination of the central nervous system in EAE rats by regulating the polarization of microglia. Int Immunopharmacol 2019;67:268-280

76. Hosseini Shamili F, Alibolandi M, Rafatpanah H, Abnous K, Mahmoudi M, Kalantari M, Taghdisi SM, Ramezani M. Immunomodulatory properties of MSC-derived exosomes armed with high affinity aptamer toward mylein as a platform for reducing multiple sclerosis clinical score. J Control Release 2019;299:149-164

77. Malmström V, Catrina AI, Klareskog L. The immunopathogenesis of seropositive rheumatoid arthritis: from triggering to targeting. Nat Rev Immunol 2017;17:6075

78. McInnes IB, Schett G. Pathogenetic insights from the treatment of rheumatoid arthritis. Lancet 2017;389:23282337

79. Benjamin O, Lappin SL. Disease Modifying Anti-Rheumatic Drugs (DMARD). 2019 Oct 2. StatPearls [Internet]. Treasure Island: StatPearls Publishing; 2019 Jan [cited 2019 Jan 2]. Available from: http://www.ncbi.nlm.nih.gov/ books/NBK507863/.

80. Cosenza S, Ruiz M, Maumus M, Jorgensen C, Noël D. Pathogenic or therapeutic extracellular vesicles in rheumatic diseases: role of mesenchymal stem cell-derived vesicles. Int J Mol Sci 2017;18:E889

81. Withrow J, Murphy C, Liu Y, Hunter M, Fulzele S, Hamrick MW. Extracellular vesicles in the pathogenesis of rheumatoid arthritis and osteoarthritis. Arthritis Res Ther 2016;18:286

82. Conforti A, Scarsella M, Starc N, Giorda E, Biagini S, Proia A, Carsetti R, Locatelli F, Bernardo ME. Microvescicles derived from mesenchymal stromal cells are not as effective as their cellular counterpart in the ability to modulate immune responses in vitro. Stem Cells Dev 2014;23: 2591-2599

83. Chen Z, Wang H, Xia Y, Yan F, Lu Y. Therapeutic potential of mesenchymal cell-derived miRNA-150-5p-expressing exosomes in rheumatoid arthritis mediated by the modulation of MMP14 and VEGF. J Immunol 2018;201: 2472-2482

84. Gao J, Xu K, Zhang G, Han J, Liu Y, Zhang L. FRI0510 the effect and mechanism of human umbilical cord mesenchymal stem cells-derived exosomes on bone destruction of collagen induced arthritis rats. Ann Rheum Dis 2019;78: 950
85. He P. AB0291E the effect of human umbilical cord mesenchymal stem cells-derived exosomes on chemokines in collagen-induced arthritis rats. Ann Rheum Dis 2019;78:1606

86. Bluestone JA, Herold K, Eisenbarth G. Genetics, pathogenesis and clinical interventions in type 1 diabetes. Nature 2010;464:1293-1300

87. Cohen DJ, St Martin L, Christensen LL, Bloom RD, Sung RS. Kidney and pancreas transplantation in the United States, 1995-2004. Am J Transplant 2006;6:1153-1169

88. Gruessner AC, Sutherland DE. Pancreas transplant outcomes for United States (US) cases as reported to the United Network for Organ Sharing (UNOS) and the International Pancreas Transplant Registry (IPTR). Clin Transpl 2008:45-56

89. Johnson PR, Jones KE. Pancreatic islet transplantation. Semin Pediatr Surg 2012;21:272-280

90. Ballinger WF, Lacy PE. Transplantation of intact pancreatic islets in rats. Surgery 1972;72:175-186

91. Chatenoud L, Primo J, Bach JF. CD3 antibody-induced dominant self tolerance in overtly diabetic NOD mice. J Immunol 1997;158:2947-2954

92. Hirsch R, Gress RE, Pluznik DH, Eckhaus M, Bluestone JA. Effects of in vivo administration of anti-CD3 monoclonal antibody on $\mathrm{T}$ cell function in mice. II. In vivo activation of T cells. J Immunol 1989;142:737-743

93. Ferran C, Dautry F, Mérite S, Sheehan K, Schreiber R, Grau G, Bach JF, Chatenoud L. Anti-tumor necrosis factor modulates anti-CD3-triggered $\mathrm{T}$ cell cytokine gene expression in vivo. J Clin Invest 1994;93:2189-2196

94. Ezquer F, Ezquer M, Contador D, Ricca M, Simon V, Conget P. The antidiabetic effect of mesenchymal stem cells is unrelated to their transdifferentiation potential but to their capability to restore $\mathrm{Th} 1 / \mathrm{Th} 2$ balance and to modify the pancreatic microenvironment. Stem Cells 2012;30: 1664-1674

95. Nakano M, Nagaishi K, Konari N, Saito Y, Chikenji T, Mizue Y, Fujimiya M. Bone marrow-derived mesenchymal stem cells improve diabetes-induced cognitive impairment by exosome transfer into damaged neurons and astrocytes. Sci Rep 2016;6:24805

96. Wen D, Peng Y, Liu D, Weizmann Y, Mahato RI. Mesenchymal stem cell and derived exosome as small RNA carrier and Immunomodulator to improve islet transplantation. J Control Release 2016;238:166-175

97. Nojehdehi S, Soudi S, Hesampour A, Rasouli S, Soleimani $M$, Hashemi SM. Immunomodulatory effects of mesenchymal stem cell-derived exosomes on experimental type-1 autoimmune diabetes. J Cell Biochem 2018;119:9433-9443

98. Rosenbaum JT. Nibbling away at the diagnosis of idiopathic uveitis. JAMA Ophthalmol 2015;133:146-147

99. Yang P. Editorial: uveitis: pathology, molecular mechanisms and therapy. Curr Mol Med 2015;15:510

100. Rosenbaum JT. Future for biological therapy for uveitis. Curr Opin Ophthalmol 2010;21:473-477

101. Zhang X, Ren X, Li G, Jiao C, Zhang L, Zhao S, Wang J, Han ZC, Li X. Mesenchymal stem cells ameliorate ex- 
perimental autoimmune uveoretinitis by comprehensive modulation of systemic autoimmunity. Invest Ophthalmol Vis Sci 2011;52:3143-3152

102. Tasso R, Ilengo C, Quarto R, Cancedda R, Caspi RR, Pennesi G. Mesenchymal stem cells induce functionally active T-regulatory lymphocytes in a paracrine fashion and ameliorate experimental autoimmune uveitis. Invest Ophthalmol Vis Sci 2012;53:786-793
103. Li G, Yuan L, Ren X, Nian H, Zhang L, Han ZC, Li X, Zhang $\mathrm{X}$. The effect of mesenchymal stem cells on dynamic changes of $T$ cell subsets in experimental autoimmune uveoretinitis. Clin Exp Immunol 2013;173:28-37

104. Bai L, Shao H, Wang H, Zhang Z, Su C, Dong L, Yu B, Chen X, Li X, Zhang X. Effects of mesenchymal stem cell-derived exosomes on experimental autoimmune uveitis. Sci Rep 2017;7:4323 